Revista Eletrônica de Direito Processual - REDP.

Rio de Janeiro. Ano 15. Volume 22. Número 2. Maio a Agosto de 2021

Periódico Quadrimestral da Pós-Graduação Stricto Sensu em Direito Processual da UERJ

Patrono: José Carlos Barbosa Moreira (in mem.). ISSN 1982-7636. pp. 120-142

www.redp.uerj.br

\title{
QUANTOS PRESOS PROVISÓRIOS? A RELAÇÃO ENTRE PRISÃO PROCESSUAL E CONGESTIONAMENTO JUDICIÁRIO ${ }^{1}$
}

HOW MANY DETAINEES? THE RELATION BETWEEN PRE-TRIAL DETENTION AND JUDICIARY CONGESTION

Antonio Henrique Graciano Suxberger

Professor do Programa de Mestrado e Doutorado em Direito do Centro Universitário de Brasília (UniCEUB). Professor do Máster Oficial em Direitos Humanos, Interculturalidade e Desenvolvimento da Universidade Pablo de Olavide (Sevilha, Espanha) e Universidade Internacional da Andaluzia. Professor Investigador associado da linha "Derechos Humanos y Desarrollo" do Programa de Doutorado em Ciências Jurídicas e Políticas da Universidade Pablo de Olavide. Professor da Fundação Escola Superior do MPDFT (FESMPDFT) e da Escola Superior do Ministério Público da União (ESMPU). Doutor e Mestre em Direito. Pós-Doutor em Direitos Humanos e Democracia pelo Ius Gentium Conimbrigae (IGC) da Universidade de Coimbra. Promotor de Justiça no Distrito Federal. Brasília/DF. ORCID http://orcid.org/0000-0003-1644-7301 E-mail: antonio.suxberger@ ceub.edu.br.

RESUMO: Por que o Brasil ostenta elevado percentual de presos provisórios? A análise dos números de prisão processual indica que a explicação não é estritamente jurídica. $\mathrm{O}$ artigo problematiza a relação entre o uso da prisão processual e os tempos de tramitação do processo criminal até a prolação da sentença por meio do cotejo entre taxa de aprisionamento e congestionamento judicial em primeira instância. Sustenta que o congestionamento judiciário é fator relevante no dimensionamento da prisão processual. Metodologicamente,

\footnotetext{
${ }^{1}$ Artigo recebido em 30/08/2020 e aprovado em 29/11/2020.
} 
Revista Eletrônica de Direito Processual - REDP.

Rio de Janeiro. Ano 15. Volume 22. Número 2. Maio a Agosto de 2021

Periódico Quadrimestral da Pós-Graduação Stricto Sensu em Direito Processual da UERJ

Patrono: José Carlos Barbosa Moreira (in mem.). ISSN 1982-7636. pp. 120-142

www.redp.uerj.br

o artigo se vale de pesquisa jurídico-exploratória e análise documental - esta última a partir dos dados disponíveis de uso da prisão no Brasil.

PALAVRAS-ChAVE: Banco Nacional de Mandados de Prisão. Congestionamento judiciário. Duração razoável do processo. Infopen. Prisão provisória.

ABSTRACT: Why Brazil presents high rates of pre-trial detention? The analysis of the numbers of pre-trial detention denotes the explication is not solely legal. The paper problematizes the relation between pre-trial detention and the length of criminal cases on first degree criminal courts until the judgment promoting comparison on imprisonment rates and judicial congestion in first instance. It asserts judicial congestion as a relevant factor to estimate pre-trial detention. Methodologically, the paper promotes legal-exploratory research and documental analysis - this, considering data available on imprisonment in Brazil.

KEYWORDS: Prison Arrests National Data. Judiciary congestion. Reasonable length of trial. Infopen. Pre-trial detention.

\section{Introdução}

A prisão processual (ou prisão provisória) caracteriza-se como a prisão imposta no curso de investigação criminal ou processo penal e se diferencia da prisão-pena, que decorre do reconhecimento da culpa do acusado como conclusão de um processo criminal. $\mathrm{Na}$ sistemática delineada pelo Código de Processo Penal, que sofreu sensível modificação na Lei n ${ }^{\circ} 13.964 / 2019$, a prisão processual pressupõe a demonstração de materialidade de crime e elementos indicativos da autoria do investigado/acusado. Como requisito - por isso, indispensável -, exige-se a demonstração da necessidade da cautela, consistente na garantia da ordem pública, da ordem econômica, na conveniência da instrução criminal ou para assegurar a aplicação da lei penal.

A prisão processual pode ser decretada como medida inicial, em casos evidentemente marcados por franca excepcionalidade, ou pode ser decretada quando medidas diversas da 
Revista Eletrônica de Direito Processual - REDP.

Rio de Janeiro. Ano 15. Volume 22. Número 2. Maio a Agosto de 2021

Periódico Quadrimestral da Pós-Graduação Stricto Sensu em Direito Processual da UERJ

Patrono: José Carlos Barbosa Moreira (in mem.). ISSN 1982-7636. pp. 120-142

www.redp.uerj.br

prisão se mostrarem insuficientes ao resguardo do caso concreto. A imposição da prisão processual, ainda, reclama a conclusão de que medidas diversas da prisão, mas igualmente possíveis no caso a partir da razão de necessidade indicada para a cautelar, não se mostrem adequadas ou suficientes, a depender da consideração da "gravidade do crime, circunstâncias do fato e condições pessoais do indiciado ou acusado" (inciso II do art. 282 do CPP).

$\mathrm{O}$ CPP delineia mais uma premissa à prisão processual: ainda que a prisão cautelar se mostre necessária no caso concreto, para que ela se imponha como lídima no curso da persecução penal, é preciso que se respeitem os prazos da persecução penal. Caso contrário, conquanto necessária, a prisão será relaxada porque ilegal.

O presente artigo tem por objetivo problematizar os dados da prisão processual no Brasil. Parte-se da premissa de que o enfrentamento do estado inconstitucional de coisas no sistema prisional brasileiro, tal como reconhecido pelo Supremo Tribunal Federal em 2015, exige clareza do problema público indicado para a apresentação de alternativas hábeis a equacionar a questão. Daí a importância dos dados que informam a questão prisional no Brasil.

O desafio posto ao uso da prisão no Brasil, em especial a prisão processual, demanda necessariamente uma abordagem que integre o saber jurídico ao contexto políticoinstitucional, de modo que o equacionamento jurídico da prisão processual permita a compreensão do direito "em ação" nas políticas públicas. A deontologia do Direito Processual Penal, que afirma a prisão processual como medida excepcional e extremada, reservada para casos últimos em que inviável o uso de cautelas diversas da prisão, se vê frustrada por razões que dizem muito com a conformação institucional do sistema de justiça criminal.

A política criminal que resulta no uso atual da prisão processual se apresenta como composição de elementos, normas, órgãos, valores, interesses, orientada à implementação de uma agenda própria, muitas vezes dissociada da afirmação simples do Direito como objetivo da política pública. São os arranjos institucionais2 do sistema de justiça que dizem mais sobre o uso da prisão que a própria dicção do Código de Processo Penal. Se a temática, pois, versa sobre a compreensão da política pública que culmina na medida extremada da

\footnotetext{
${ }^{2}$ BUCCI, Maria Paula Dallari, Fundamentos para uma teoria jurídica das políticas públicas, São Paulo: Saraiva, 2013, p. 184-185.
} 
Revista Eletrônica de Direito Processual - REDP.

Rio de Janeiro. Ano 15. Volume 22. Número 2. Maio a Agosto de 2021

Periódico Quadrimestral da Pós-Graduação Stricto Sensu em Direito Processual da UERJ

Patrono: José Carlos Barbosa Moreira (in mem.). ISSN 1982-7636. pp. 120-142

www.redp.uerj.br

prisão processual, a decisão da ação pública deve se amparar em dados confiáveis. 3 Por isso, a destacada importância de um banco de dados sistematizado e preciso sobre os números prisionais, que permita um manejo das redes de atuação do sistema de justiça com mínima credibilidade.

A partir da análise dos números de prisão processual, é possível indicar vetores explicativos de sua incidência que não tenham fundamento estritamente jurídico? $\mathrm{Na}$ compreensão dos números de prisão processual no Brasil, como se conforma seu uso em face do número total de pessoas presas no país e dos tempos de tramitação do processo criminal até a prolação da sentença?

Há estudos que problematizam as temáticas racial e de gênero na construção das decisões que impõem prisão processual às pessoas apresentadas ao sistema de justiça criminal.4 As decisões seriam resultado de um punitivismo estatal que materializa a hegemonia de uma classe dominante sobre outra oprimida e vulnerável. No entanto, a partir das bases hoje existentes de compreensão dos números de prisão no Brasil, não há clareza na compreensão dos dados de encarceramento e, mesmo em relação aos dados tal como divulgados, há frequentemente assimetrias e incongruências entre as bases de dados e nas comparações entre unidades federativas e justiças estadual e federal.

O alerta de Débora Pastana permanece atual ao destacar que o Estado brasileiro manifesta uma "democracia tutelada", no sentido de que o Estado testa o limite democrático, mas não o suprime em termos estritamente legais, de modo que os problemas da institucionalidade redundam em práticas punitivas em regra justificadas como respostas emergenciais. 5 No entanto, adianta-se um ponto de discordância em face da mesma autora, quando esta afirma que o investimento maciço no enfrentamento da criminalidade redunda na configuração do Estado punitivo.6 Isso porque a avaliação dos números de prisão processual no Brasil parece

\footnotetext{
3 WERNER, Patricia Ulson Pizarro, A abordagem Direito e Políticas Públicas como ferramenta de aprimoramento das instituições jurídicas: qualidade organizacional, sistematização de dados e fomento das relações interinstitucionais, REI - Revista Estudos Institucionais, v. 5, n. 3, p. 926-941, 2019, p. 932.

${ }^{4}$ LAGES, Lívia Bastos et al, Os determinantes da prisão preventiva na Audiência de Custódia: reforço de estereótipos sociais?, Revista Direito GV, v. 15, n. 3, 2019; KULLER, Laís; DIAS, Camila, O papel do preso nas audiências de custódia: Protagonista ou marginal?, Dilemas - Revista de Estudos de Conflito e Controle Social, v. 12, n. 2, p. 267-287, 2019.

${ }^{5}$ PASTANA, Debora Regina, Os contornos do Estado punitivo no Brasil, Revista da Faculdade de Direito UFPR, v. 46, n. 0, p. 207-221, 2007, p. 216.

${ }^{6}$ PASTANA, Débora Regina, Estado punitivo brasileiro: A indeterminação entre democracia e autoritarismo, Civitas - Revista de Ciências Sociais, v. 13, n. 1, p. 27-47, 2013, p. 28.
} 
Revista Eletrônica de Direito Processual - REDP.

Rio de Janeiro. Ano 15. Volume 22. Número 2. Maio a Agosto de 2021

Periódico Quadrimestral da Pós-Graduação Stricto Sensu em Direito Processual da UERJ

Patrono: José Carlos Barbosa Moreira (in mem.). ISSN 1982-7636. pp. 120-142

www.redp.uerj.br

indicar que o recrudescimento dos quadros punitivos - fora do quadro de estrita legalidade

- dá-se justamente nos contextos de mais reduzida institucionalidade da justiça criminal. A baixa institucionalidade é compreendida como a reduzida capacidade de articulação do Estado na exteriorização de suas ações públicas7 (no caso, a materialização do serviço prestado pela justiça criminal).

O artigo tem por hipótese aferir se a conformação do uso da prisão processual se dá em contextos com prazos mais alargados de duração do processo em primeira instância. E, em caso de resposta afirmativa, discutir se essa situação deriva de solução normativa ao problema ou da conformação da institucionalidade da justiça criminal.

Metodologicamente, o artigo se vale de pesquisa jurídico-exploratória8, valendo-se da técnica de análise documental, consistente nos bancos de dados de publicidade ativa referentes aos números de presos em cumprimento de pena e presos provisórios, além dos diagnósticos do Conselho Nacional de Justiça sobre as taxas de congestionamento judicial e os tempos de tramitação de processos criminais em primeira instância.

\section{Os números de prisão processual}

O que dizem os números sobre a prisão processual penal no Brasil?

Em 3 de julho de 2020, o CNJ indicava 874.132 pessoas privadas de liberdade em seu Banco Nacional de Mandados de Prisão (BNMP), cuja composição merece comentários mais detidos.9 Os indicados como "presos" totalizam 871.667 pessoas, de acordo com a seguinte apresentação: 387.587 presos provisórios, 193.191 presos em execução provisória, 289.530 presos em execução definitiva, e 1.359 presos em decorrência de dívida (pensão alimentícia). Ainda, há a indicação de 2.465 internados, dos quais 509 são provisórios, 361 se encontram em execução provisória e 1.595 estão em execução definitiva.

Registre-se que, para os fins do BNMP, a categoria "preso provisório" (assim como o "internado provisório") refere-se ao preso cujo processo ainda não foi sentenciado. Porque,

\footnotetext{
${ }^{7}$ BUCCI, Fundamentos para uma teoria jurídica das políticas públicas, p. 144.

${ }^{8}$ GUSTÍN, Miracy Barbosa de Sousa; DIAS, Maria Tereza Fonseca, (Re)pensando a pesquisa jurídica: teoria e prática, 3. ed. Belo Horizonte: Del Rey, 2010, p. 27-28.

${ }^{9}$ BRASIL, Conselho Nacional de Justiça (CNJ), Portal do BNMP [Banco Nacional de Mandados de Prisão]. Versão 1.15.1 [recurso on-line], Brasília: CNJ, 2020.
} 
Revista Eletrônica de Direito Processual - REDP.

Rio de Janeiro. Ano 15. Volume 22. Número 2. Maio a Agosto de 2021

Periódico Quadrimestral da Pós-Graduação Stricto Sensu em Direito Processual da UERJ

Patrono: José Carlos Barbosa Moreira (in mem.). ISSN 1982-7636. pp. 120-142

www.redp.uerj.br

seguidamente à sentença, ainda que não tenha ocorrido o trânsito em julgado, o preso é considerado em execução provisória da sentença - nos termos do que determina o enunciado 716 da súmula do STF.10

Assim, pelo BNMP do CNJ, o Brasil ostentaria um percentual de $44,46 \%$ de presos provisórios. O número preciso pode ser pior. É que o total de “presos", para se alcançar esse percentual, é de 871.667 (isto é, o total indicado pelo BNMP excluídos os internados). No entanto, a própria acepção de "preso" deve ser objeto de reflexão.

No Brasil, aquele que se encontra em regime aberto de cumprimento da pena não se encontra recolhido à prisão. Não há casas de albergado (art. 93-95 da Lei de Execução Penal) no Brasil, que são os estabelecimentos penais para alocação de pessoas que se encontrem em regime aberto de cumprimento de pena. Já aquele que cumpre a pena em regime semiaberto, por lei, estaria recolhido em colônia (agrícola, industrial ou similar). Porém, seguidamente à edição do enunciado 56 da súmula vinculante do STF11, são muitos os estados brasileiros cujos "presos" em regime semiaberto, verdadeiramente, não se encontram mais recolhidos em estabelecimentos penais.

Tais considerações são relevantes para se notar que "preso" não é sinônimo, hoje, de pessoa recolhida em estabelecimento penal. Aliás, não há hoje base de dados, em regime de publicidade ativa,12 que assegure, com precisão e certeza, o número de pessoas recolhidas em estabelecimentos prisionais no Brasil. Assim, o percentual de presos provisórios (ao tomar como o todo o número total de pessoas em cumprimento de pena privativa de liberdade somado ao número de presos provisórios), se cotejado com o número de pessoas efetivamente recolhidas a estabelecimentos penais pode alcançar patamar muito mais elevado.

\footnotetext{
${ }^{10}$ BRASIL, Supremo Tribunal Federal (STF), Súmula 716: Admite-se a progressão de regime de cumprimento da pena ou a aplicação imediata de regime menos severo nela determinada, antes do trânsito em julgado da sentença condenatória. Pleno, 24 set. 2003.

${ }^{11}$ BRASIL, Supremo Tribunal Federal (STF), Súmula Vinculante 56: A falta de estabelecimento penal adequado não autoriza a manutenção do condenado em regime prisional mais gravoso, devendo-se observar, nessa hipótese, os parâmetros fixados no RE 641.320/RS. Pleno. 29/6/2016.

${ }^{12}$ Por publicidade ativa se entende a divulgação das informações de interesse coletivo ou geral que sejam de responsabilidade de órgãos e entidades públicas, nos termos do $\S 1^{\circ}$ do art. $8^{\circ}$ Lei $n^{\circ} 12.527 / 2011$ (Lei de Acesso à Informação).
} 
Revista Eletrônica de Direito Processual - REDP.

Rio de Janeiro. Ano 15. Volume 22. Número 2. Maio a Agosto de 2021

Periódico Quadrimestral da Pós-Graduação Stricto Sensu em Direito Processual da UERJ

Patrono: José Carlos Barbosa Moreira (in mem.). ISSN 1982-7636. pp. 120-142

www.redp.uerj.br

Essa é uma percepção que escapa de todas as bases que apresentam o contexto prisional no Brasil. CNJ, CNMP13 e Departamento Penitenciário Nacional não dispõem dos números que considerem o número de pessoas efetivamente recolhidas em estabelecimento penal. Afinal, cumprimento de pena privativa de liberdade não é sinônimo de preso - e essa compreensão normativa ganhou ainda mais relevo com a disseminação de providências dirigidas ao encarceramento assumidas após o reconhecimento do estado inconstitucional de coisas no sistema prisional.14 Falta, pois, confiabilidade às bases de dados 15, porque se mostram invariavelmente imprecisas.

Os dados do CNJ são bem discrepantes quando cotejados com os números do Departamento Penitenciário Nacional (DEPEN). O DEPEN, cujo sistema de acompanhamento da execução das penas, da prisão cautelar e da medida de segurança é regulamentado pela Lei ${ }^{\circ} 12.714 / 2012$, formalizou por último seus dados referentes ao mês de novembro de 2019 - o quadro quantitativo se mostra sensivelmente discrepante em face do CNJ.

O DEPEN indica como total de "presos em unidades prisionais no Brasil" o número de 748.009 pessoas. Tal como ocorre com o BNMP, o Infopen registra o número de pessoas que se encontra em cumprimento de pena privativa de liberdade, o que não é sinônimo de pessoas efetivamente recolhidas à prisão. O detalhamento do total de "presos em unidades" é assim indicado: 362.547 em regime fechado (é dizer, efetivamente recolhidas à prisão); 133.408 em regime semiaberto (eis o número inconcluso quanto ao efetivo recolhimento à prisão); 25.137 em regime aberto (verdadeiramente em prisão domiciliar, pois inexistem casas de albergado); 222.558 presos provisórios (pessoas presas, efetivamente recolhidas à prisão, sem título condenatório); 250 pessoas em tratamento ambulatorial (ou seja, não se

\footnotetext{
${ }^{13}$ BRASIL, Conselho Nacional do Ministério Público (CNMP), Sistema Prisional em Números. Relatórios BI - Resolução CNMP 56/2010. Versão compilada e atualizada on-line, Atualização on-line.

${ }^{14}$ BRASIL, Supremo Tribunal Federal (STF), Medida Cautelar na Arguição de Descumprimento de Preceito Fundamental no 347 (ADPF 347 MC). Distrito Federal. Pleno. Rel. Min. Marco Aurélio. Julgamento em 9 set. 2015.

15 CRESPO, André Pereira; VARELLA, Marcelo Dias, A insuficiência das políticas públicas no sistema penitenciário para responder ao estado de coisas inconstitucional: um problema comum a todos os poderes, R. Fac. Dir. UFG, v. 43, p. 1-24, 2019, p. 7.
} 
Revista Eletrônica de Direito Processual - REDP.

Rio de Janeiro. Ano 15. Volume 22. Número 2. Maio a Agosto de 2021

Periódico Quadrimestral da Pós-Graduação Stricto Sensu em Direito Processual da UERJ

Patrono: José Carlos Barbosa Moreira (in mem.). ISSN 1982-7636. pp. 120-142

www.redp.uerj.br

encontram internadas); 4.109 em medida de segurança (internadas em estabelecimento manicomial). 16

Pelos números do DEPEN, com a ressalva mencionada - aplicável também aos dados do DEPEN - de que o total não é exatamente de pessoas recolhidas à prisão, o percentual de presos provisórios seria de $29,75 \%$. A diferença entre os $44,46 \%$ indicados pelo CNJ e os 29,75\% de presos provisórios indicados pelo DEPEN evidencia, em referência a um mesmo país, duas percepções distintas da realidade. De um lado, a percepção de um país com equacionamento razoável da prisão processual, segundo o DEPEN. De outro lado, um país com um sistema de justiça criminal que faz uso desvirtuado da prisão, segundo o CNJ. Como nota agravante, o fato de que, tanto num sistema quanto noutro, o total sobre o qual se calcula esse percentual não evidencia, verdadeiramente, o número de pessoas recolhidas à prisão.

Enfim, o quadro da prisão processual mostra-se pouco preciso. Se fosse uma imagem, seu observador só conseguiria enxergar de maneira turva, obnubilada. De qualquer forma, ainda que impreciso, uma constatação é clara: esse quadro é ruim.

O World Prison Brief (WPB), plataforma on-line que tem a pretensão de reunir os dados prisionais de todos os países, organiza os dados ali reunidos comparando taxas de encarceramento, números absolutos, presos provisórios, entre outros. ${ }^{17}$ É impressionante que os percentuais mais elevados de presos provisórios são ostentados por países com níveis baixos de desenvolvimento humano ou dotados de sistemas de justiça com reduzida institucionalidade.18 O Brasil, nesse quadro, apresenta um percentual de 30,4\% de presos provisórios - número fornecido pelo Ministério da Justiça e Segurança Pública, segundo o próprio WPB, o que fixaria o Brasil na $103^{\mathrm{a}}$ posição no ranking de países (do maior para o menor) com mais elevados percentuais de presos provisórios.

\footnotetext{
16 BRASIL, Ministério da Justiça e Segurança Pública. Departamento Penitenciário Nacional (DEPEN), Levantamento Nacional de Informações Penitenciárias: INFOPEN Atualização — Dezembro de 2019 , Brasília: DEPEN, 2019.

17 INSTITUTE FOR CRIMINAL POLICY RESEARCH (ICPR); BIRBECK UNIVERSITY OF LONDON, World Prison Brief (WPF) data. Highest to Lowest. [recurso eletrônico], Londres: Birbeck University of London, 2020.

1818 A título ilustrativo, eis os dez países com maior taxa de encarceramento (número de presos por 100 mil habitantes) do mundo: EUA, El Salvador, Turmequistão, Tailândia, Palau, Ruanda, Cuba, Ilhas Maldivas, Ilhas Mariana (EUA) e Ilhas Virgens (Reino Unido). O Brasil aparece na $21^{\mathrm{a}}$ posição com 357 presos a cada 100 mil habitantes - com a ressalva já lançada sobre o que se entende por "preso" nesse cômputo. E estes são os dez países com os maiores percentuais de presos provisórios do mundo: Líbia, San Marino, Bangladesh, Gabão, Paraguai, Benin, Filipinas, Haiti, Liechtenstein, República Democrática do Congo. Cf. Ibid.
} 
Revista Eletrônica de Direito Processual - REDP.

Rio de Janeiro. Ano 15. Volume 22. Número 2. Maio a Agosto de 2021

Periódico Quadrimestral da Pós-Graduação Stricto Sensu em Direito Processual da UERJ

Patrono: José Carlos Barbosa Moreira (in mem.). ISSN 1982-7636. pp. 120-142

www.redp.uerj.br

Apenas por curiosidade, caso se aplique o percentual indicado pelo CNJ de 44,46\%, o Brasil se situaria na $55^{\mathrm{a}}$ posição, acima do Quênia e abaixo do Guão (território da Micronésia, Oceania, incorporado pelos Estados Unidos da América). Veja-se que, no ranqueamento de países de modo decrescente, os percentuais de presos provisórios não guardam aproximação com as taxas de encarceramento: os países com as mais elevadas taxas de encarceramento no mundo não são os que têm as mais elevadas taxas de presos provisórios. Os países com as mais elevadas taxas de prisão processual são, invariavelmente, países de reduzida institucionalidade e com gravíssimos quadros de pobreza e/ou desigualdade social.

O uso da prisão processual, no mundo todo, apresentou um aumento de aproximadamente $15 \% .{ }^{19}$ Em estudo utilizando os dados do WPF, Catherine Heard e Helen Fair indicaram que o Brasil, especificamente, apresentou um crescimento de $643 \%$ de presos provisórios de 1994 a 2019. Se o crescimento impressiona por si só, ele ganha mais significado quando se percebe que população geral de presos, nesse mesmo período, experimentou aumento de $478 \% .{ }^{20}$ É dizer: se o aumento do uso da prisão é patente na realidade brasileira ao longo dos anos, essa percepção é substancialmente incrementada quando se visualiza o uso da prisão processual. Vale o registro de que, para o estudo, as autoras consideraram o percentual de 30,3\% de presos provisórios no Brasil - dado que, como indicado, é inferior ao que efetivamente demonstra o cômputo que considera os processos e investigações em curso no sistema de justiça criminal. O percentual de crescimento se apresenta modesto, pois não considerou o indicativo mais gravoso do contexto nacional.

A discrepância entre DEPEN e CNJ é grande. Vê-se uma diferença de 126.123 no cômputo total de "presos" em unidades prisionais. Para os fins do presente estudo, a dissonância mais relevante encontra-se na diferença entre os números de presos provisórios: 165.029 pessoas. Essa diferença - muitíssimo alargada - dá-se por conta de um flagrante quadro de ilegalidade que perdura há muitos anos no Brasil: o número de pessoas presas em delegacias de polícia.

\footnotetext{
${ }^{19}$ HEARD, Catherine; FAIR, Helen, Pre-trial detention and its over-use: evidence from ten countries, Londres: ICPR; University of London, 2019, p. 2.

${ }^{20}$ Ibid., p. 5.
} 
Revista Eletrônica de Direito Processual - REDP.

Rio de Janeiro. Ano 15. Volume 22. Número 2. Maio a Agosto de 2021

Periódico Quadrimestral da Pós-Graduação Stricto Sensu em Direito Processual da UERJ

Patrono: José Carlos Barbosa Moreira (in mem.). ISSN 1982-7636. pp. 120-142

www.redp.uerj.br

Como o DEPEN só computa os números de estabelecimentos penais, as pessoas alocadas em carceragens policiais (Delegacias e/ou Superintendências) - em quadro, repitase, de ilegalidade flagrante - não aparecem nos dados do DEPEN. Já o CNJ realiza seu cômputo por dados hauridos de processos em trâmite. Tem-se aí a razão de diferença no número de presos provisórios. Uma das poucas, senão a única, base de dados que registra presos alocados em estabelecimentos policiais é o sistema mantido pelo Conselho Nacional do Ministério Público, construído a partir dos relatórios de inspeção preenchidos no exercício do controle externo da atividade policial pelo Ministério Público. ${ }^{21}$ No entanto, por não se referir exatamente a dados de estruturas prisionais, seu regime de publicidade é restrito, isto é, não há indicação expressa e acessível diretamente do número de pessoas alocadas nas carceragens policiais.

Uma constatação se extrai da análise dos dados de encarceramento (geral) e de prisão processual: se o uso da prisão, de um modo amplo, diz respeito à opção política dirigida a esse tipo de resposta à criminalidade; o uso da prisão processual guarda proximidade não apenas com essa opção política mas, sobretudo, com as disfuncionalidades do sistema de justiça que se mostre incapaz de resolver os casos que lhe chegam de maneira precária e alargada no tempo. Essa percepção se extrai dos números que noticiam os tempos dos processos criminais em primeira instância.

\section{Congestionamento judiciário como fator explicativo da prisão processual}

A taxa de congestionamento é o indicador que mede "o percentual de casos que permaneceram pendentes de solução ao final do ano-base, em relação ao que tramitou (soma dos pendentes e dos baixados)". ${ }^{22}$ Trata-se, portanto, de parâmetro de aferição do percentual dos processos que ficam represados sem solução, comparativamente ao total tramitado no período de um ano.

\footnotetext{
${ }^{21}$ BRASIL, Conselho Nacional do Ministério Público (CNMP), O Ministério Público e o controle externo da Atividade Policial: Dados 2016 [recurso eletrônico], Brasília: CNMP, 2017.

${ }^{22}$ BRASIL, Conselho Nacional de Justiça (CNJ), Justiça em Números 2019. Relatório Analítico [recurso online], Brasília: CNJ, 2019, p. 78.
} 
Revista Eletrônica de Direito Processual - REDP.

Rio de Janeiro. Ano 15. Volume 22. Número 2. Maio a Agosto de 2021

Periódico Quadrimestral da Pós-Graduação Stricto Sensu em Direito Processual da UERJ

Patrono: José Carlos Barbosa Moreira (in mem.). ISSN 1982-7636. pp. 120-142

www.redp.uerj.br

Quanto maior o índice, maior a dificuldade do tribunal em lidar com seu estoque de processos. Dentro desses cômputos, o CNJ calcula a taxa de congestionamento líquida ${ }^{23}$, que é calculada a partir da desconsideração dos processos suspensos, sobrestados ou em arquivo provisório em face de todo o acervo. O cômputo da taxa líquida é relevante porque há processos que, embora tramitem rapidamente, não podem ser "baixados" - é o que acontece com os processos de execução da pena, que só são extintos após o cumprimento da pena. Daí a importância da taxa líquida, em especial para a verificação dos trâmites da justiça criminal em primeira instância.

Para além da consideração de que os Estados fazem uso da pena privativa de liberdade de maneira diferente entre si - dada a variação substancial das taxas de encarceramento -, essas assimetrias igualmente se observam quando se visualiza a taxa de congestionamento dos Tribunais. A variação é regional e igualmente presente quando comparamos Justiça estadual e Justiça federal.

A Justiça estadual, considerada em sua totalidade, apresenta um percentual de 73,9\% de congestionamento - são índices que vão de 53,5\% no Tribunal de Justiça de Roraima a 82,1\% no Judiciário de Santa Catarina. Na Justiça Federal, o Tribunal da $5^{\text {a }}$ região (que abrange os seguintes Estados: Alagoas, Ceará, Paraíba, Pernambuco, Rio Grande do Norte e Sergipe) tem percentual de 59,8\% (a menor taxa da Justiça Federal); já o Tribunal da $3^{\text {a }}$ Região (São Paulo e Mato Grosso do Sul) tem a mais elevada taxa de congestionamento com $74,6 \%$.

A aferição dos números de congestionamento se mostra, muitas vezes, de compreensão difícil. Basta verificar o que isso implica em relação ao tempo de tramitação do processo até a prolação da sentença. O seguinte excerto do sumário executivo do Relatório de 2019 elaborado pelo CNJ dá a dimensão do problema, isto é, como o congestionamento se projeta nos tempos de tramitação dos processos em primeira instância: No primeiro grau, em média, o tempo de tramitação na fase de conhecimento do processo criminal é maior que o não criminal em todos os ramos de Justiça. Enquanto na Justiça Estadual o tempo médio de tramitação de uma ação não criminal no primeiro grau é de 2 anos e 5 meses, na esfera criminal, ela sobe para 3 anos e 10 meses. Na Federal, a primeira

\footnotetext{
${ }^{23}$ Ibid., p. 95.
} 
Revista Eletrônica de Direito Processual - REDP.

Rio de Janeiro. Ano 15. Volume 22. Número 2. Maio a Agosto de 2021

Periódico Quadrimestral da Pós-Graduação Stricto Sensu em Direito Processual da UERJ

Patrono: José Carlos Barbosa Moreira (in mem.). ISSN 1982-7636. pp. 120-142

www.redp.uerj.br

instância leva 1 ano e 11 meses para analisar um processo não criminal e 2 anos e 3 meses para o criminal. ${ }^{24}$

Apenas a título comparativo, num guia de atuação editado no ano de 2009, seguidamente às reformas do Código de Processo Penal nos temas atinentes às provas, aos procedimentos e, em especial, ao procedimento dos crimes dolosos contra a vida (júri), o CNJ indicou como tempo geral de contagem dos prazos processuais do procedimento comum, rito ordinário, o prazo de 105 dias até prolação de sentença quando o acusado se encontrar preso e assistido por defensor constituído. Essa projeção atende ao ordinário das situações, isto é, casos em que não venham a ocorrer situações excepcionais ou justificadas posteriormente. O próprio documento ressalva que “(...) não há uma regra absoluta e a contagem demonstrada a seguir é apenas uma referência, suscetível de sofrer oscilações diante de peculiaridades do caso concreto, pois a jurisprudência já afastou a contagem aritmética de prazos processuais". ${ }^{25}$

De qualquer modo, a indicação genérica, ainda que possa ganhar extensões previsíveis em alguns casos (nomeação de defensor dativo, prazos distintos para a investigação na Justiça Federal etc.), já mostra o quanto o congestionamento afeta o equacionamento da prisão processual na justiça criminal em primeira instância.

Os Estados de São Paulo, Minas Gerais, Rio de Janeiro, Paraná e Rio Grande do Sul são, em números absolutos, os que ostentam os mais elevados números de casos criminais pendentes para o ano de 2019. No entanto, a comparação de números absolutos pouco diz para a compreensão da prisão processual: afinal, seria necessário cotejar os números de serviços à disposição (juízes, membros do Ministério Público, serviços de assistência judiciária em geral e outros) e os números populacionais.

Interessam, pois, os dados de tempo médio de tramitação dos processos. Como a pergunta da presente investigação dirige-se à prisão processual - aquela estabelecida até a prolação de sentença em primeira instância -, merece destaque o tempo de tramitação das ações penais na justiça de primeira instância (excluído, assim, o tempo de tramitação nos

\footnotetext{
${ }^{24}$ BRASIL, Conselho Nacional de Justiça (CNJ), Justiça em Números 2019: Sumário Executivo [recurso online], Brasília: CNJ, 2019, p. 14.

${ }^{25}$ BRASIL, Conselho Nacional de Justiça (CNJ), Manual Prático de Rotinas das Varas Criminais e de Execução Penal: Elaborado de acordo com o plano de gestão para o funcionamento das varas criminais e de execução penal, Brasília: CNJ, 2009, p. 28.
} 
Revista Eletrônica de Direito Processual - REDP.

Rio de Janeiro. Ano 15. Volume 22. Número 2. Maio a Agosto de 2021

Periódico Quadrimestral da Pós-Graduação Stricto Sensu em Direito Processual da UERJ

Patrono: José Carlos Barbosa Moreira (in mem.). ISSN 1982-7636. pp. 120-142

www.redp.uerj.br

tribunais de segundo grau de jurisdição e nos tribunais superiores). Segundo esse critério, o tempo médio de tramitação das ações penais na Justiça Estadual é de 3 anos e 10 meses. Na Justiça Federal, o tempo médio de tramitação das ações penais em primeira instância é de 2 anos e 3 meses.26 Os cômputos dos tempos médios, no caso da Justiça Federal, consideram as organizações dos Tribunais Regionais Federais em regiões e, mesmo na Justiça Federal, vê-se variação grande na consideração dos tempos de tramitação entre as Seções Judiciárias vinculadas a cada Região.

Quando se dispõe do tempo médio de tramitação da ação penal em primeira instância, pode-se, então, traçar um paralelo entre esses tempos do fluxo em primeira instância e os percentuais de presos provisórios27 que apresentam tanto os Estados, no exercício da competência comum estadual, quanto as regiões da Justiça Federal. Lançados esses dados num quadro comparativo, chega-se ao seguinte:

\begin{tabular}{|c|c|c|c|}
\hline Estado & $\begin{array}{ll}\text { Tempo } & \text { de } \\
\text { duração28 }\end{array}$ & $\begin{array}{ll}\text { Percentual de } & \text { des } \\
\text { Presos } & \\
\text { provisórios29 } & \end{array}$ & $\begin{array}{l}\text { Percentual de } \\
\text { provisórios sem a } \\
\text { consideração do } \\
\text { sistema de segurança } \\
\text { pública } \\
\text { (Delegacias)30 }\end{array}$ \\
\hline $\mathrm{AC}$ & 2 anos e 5 meses & $35,13 \%$ & $26,37 \%$ \\
\hline $\mathrm{AL}$ & 6 anos & $60,33 \%$ & $33,57 \%$ \\
\hline $\mathrm{AM}$ & 3 anos e 8 meses & $53,91 \%$ & $28,18 \%$ \\
\hline AP & 1 ano e 12 meses & $52,53 \%$ & $21,49 \%$ \\
\hline BA & 4 anos e 3 meses & 42,96 & $48,76 \%$ \\
\hline
\end{tabular}

26 Todos os dados de tempo médio de tramitação das ações penais são extraídos de: BRASIL, Justiça em Números 2019. Relatório Analítico [recurso on-line], p. 163.

${ }^{27}$ Para a presente comparação, os percentuais de presos provisórios foram alcançados pelos números do CNJ, por meio do cálculo do total de presos provisórios sobre o total de "presos" - expressão que se refere, como já explicado, ao número de pessoas em cumprimento de pena privativa de liberdade somado aos números de presos provisórios e de pessoas em prisão civil (pensão alimentícia). Cf. BRASIL, Portal do BNMP [Banco Nacional de Mandados de Prisão]. Versão 1.15.1 [recurso on-line].

${ }^{28}$ BRASIL, Justiça em Números 2019. Relatório Analítico [recurso on-line], p. 163.

${ }^{29}$ BRASIL, Portal do BNMP [Banco Nacional de Mandados de Prisão]. Versão 1.15.1 [recurso on-line].

${ }^{30}$ Percentuais alcançados a partir da consideração do número de presos provisórios em proporção ao total de "presos em unidades prisionais" (este último número subtraído do quantitativo de internações e de pessoas em tratamento ambulatorial). Cf. BRASIL, Infopen. 
Revista Eletrônica de Direito Processual - REDP.

Rio de Janeiro. Ano 15. Volume 22. Número 2. Maio a Agosto de 2021

Periódico Quadrimestral da Pós-Graduação Stricto Sensu em Direito Processual da UERJ

Patrono: José Carlos Barbosa Moreira (in mem.). ISSN 1982-7636. pp. 120-142

www.redp.uerj.br

\begin{tabular}{|c|c|c|c|}
\hline $\mathrm{CE}$ & $\begin{array}{l}3 \text { anos e } 12 \\
\text { meses }\end{array}$ & $46,69 \%$ & $46,42 \%$ \\
\hline DF31 & 11 meses & $25,24 \%$ & $17,46 \%$ \\
\hline ES & $\begin{array}{l}3 \text { anos e } 11 \\
\text { meses }\end{array}$ & $38,82 \%$ & $33,53 \%$ \\
\hline GO & 3 anos e 3 meses & $54,97 \%$ & $40,85 \%$ \\
\hline MA & $\begin{array}{l}3 \quad \text { anos e } 12 \\
\text { meses }\end{array}$ & $48,23 \%$ & $36,10 \%$ \\
\hline MG & 2 anos e 8 meses & $43,88 \%$ & $39,62 \%$ \\
\hline MS & 2 anos e 4 meses & $26,28 \%$ & $23,99 \%$ \\
\hline MT & 3 anos e 6 meses & $53,52 \%$ & $45,29 \%$ \\
\hline PA & $\begin{array}{l}3 \text { anos e } 12 \\
\text { meses }\end{array}$ & $46,41 \%$ & $28,09 \%$ \\
\hline PB & 3 anos e 3 meses & $28,34 \%$ & $31,74 \%$ \\
\hline $\mathrm{PE}$ & 3 anos e 9 meses & $35,46 \%$ & $36,62 \%$ \\
\hline PI & $\begin{array}{l}4 \text { anos e } 11 \\
\text { meses }\end{array}$ & $38,32 \%$ & $44,74 \%$ \\
\hline PR & 2 anos e 4 meses & $53,52 \%$ & $29,31 \%$ \\
\hline RJ & $\begin{array}{l}2 \quad \text { anos } \text { e } 11 \\
\text { meses }\end{array}$ & $72,50 \%$ & $38,94 \%$ \\
\hline $\mathrm{RN}$ & 2 anos e 3 meses & $53,62 \%$ & $28,23 \%$ \\
\hline $\mathrm{RO}$ & 1 ano e 11 meses & $18,70 \%$ & $13,10 \%$ \\
\hline $\mathrm{RR}$ & 2 anos e 5 meses & $32,12 \%$ & $27,59 \%$ \\
\hline $\mathrm{RS}$ & 8 anos e 2 meses & $47,94 \%$ & $29,76 \%$ \\
\hline $\mathrm{SC}$ & 2 anos e 2 meses & $32,13 \%$ & $35,62 \%$ \\
\hline SE & 2 anos e 5 meses & $75,70 \%$ & $45,75 \%$ \\
\hline SP & 6 anos e 3 meses & $35,16 \%$ & $20,13 \%$ \\
\hline TO & 1 ano e 10 meses & $46,64 \%$ & $35,62 \%$ \\
\hline
\end{tabular}

31 Conquanto o Judiciário do Distrito Federal seja organizado e mantido pela União, situando-se organizacionalmente como uma Justiça "federal", sua competência criminal é comum estadual. Daí sua consideração juntamente com as justiças dos Estados. 
Revista Eletrônica de Direito Processual - REDP.

Rio de Janeiro. Ano 15. Volume 22. Número 2. Maio a Agosto de 2021

Periódico Quadrimestral da Pós-Graduação Stricto Sensu em Direito Processual da UERJ

Patrono: José Carlos Barbosa Moreira (in mem.). ISSN 1982-7636. pp. 120-142

www.redp.uerj.br

\begin{tabular}{|l|l|l|l|}
\hline Média & $\begin{array}{l}3 \text { anos e } 10 \\
\text { meses }\end{array}$ & $44,46 \%$ & $29,92 \% 32$ \\
\hline
\end{tabular}

Quando se aplica o mesmo percurso metodológico em relação à Justiça Federal em primeira instância33, chega-se ao quadro a seguir:

\begin{tabular}{|l|l|l|}
\hline Região & $\begin{array}{l}\text { Tempo de } \\
\text { duração34 }\end{array}$ & $\begin{array}{l}\text { Percentual de } \\
\text { Presos } \\
\text { provisórios35 }\end{array}$ \\
\hline $1^{\text {a36 }}$ & 1 ano e 6 meses & $43,15 \%$ \\
\hline $2^{\text {a37 }}$ & 2 anos e 4 meses & $64,15 \%$ \\
\hline $3^{\text {a33 }}$ & 5 anos e 4 meses & $34,38 \%$ \\
\hline $4^{\text {a39 }}$ & 1 ano e 9 meses & $43,64 \%$ \\
\hline $5^{\text {a40 }}$ & 2 anos e 12 meses & $42,74 \%$ \\
\hline Média & 2 anos e 3 meses & $43,14 \%$ \\
\hline
\end{tabular}

Esse cotejo se mostra tão mais importante quando se percebe quão inconsistentes são as bases de dados da temática prisional. Apenas a título ilustrativo, considere-se o Estado do Rio de Janeiro, com seus espantosos 72,5\% de presos provisórios, de acordo com os dados do CNJ. Caso se busque o percentual de presos provisórios com base nos números do DEPEN, chega-se ao percentual de 38,94\%. O que explica esse disparate? Um dos fatores

\footnotetext{
${ }^{32}$ O percentual de $29,92 \%$ contrasta com o percentual de $29,75 \%$ indicado no início da presente seção porque, na construção da tabela, o total de "presos" é alcançado depois de subtrair do número indicado pelo DEPEN os números de internados e de pessoas em tratamento ambulatorial. Daí, a variação.

${ }^{33}$ Vale o registro de que os dados do DEPEN, para o sistema prisional federal, diz respeito ao uso das prisões de segurança máxima, nos termos da Lei no 11.671/2008. Logo, a alocação de 673 presos no sistema federal (dos quais 99 são provisórios) não diz respeito exatamente a presos de processos da competência da justiça federal, mas sim presos direcionados aos estabelecimentos de segurança máxima do sistema federal. Assim, seria irrelevante o quadro comparativo entre dados do DEPEN e do CNJ nesse aspecto.

${ }^{34}$ BRASIL, Justiça em Números 2019. Relatório Analítico [recurso on-line], p. 163.

${ }^{35}$ BRASIL, Portal do BNMP [Banco Nacional de Mandados de Prisão]. Versão 1.15.1 [recurso on-line].

${ }^{36} \mathrm{O}$ Tribunal Regional Federal da $1^{a}$ Região abrange as seções judiciárias da Justiça Federal nos seguintes Estados: Acre, Amapá, Amazonas, Bahia, Distrito Federal, Goiás, Maranhão, Mato Grosso, Minas Gerais, Pará, Piauí, Rondônia, Roraima e Tocantins.

${ }^{37}$ O Tribunal Regional Federal da $2^{a}$ Região abrange as seções judiciárias da Justiça Federal nos seguintes Estados: Rio de Janeiro e Espírito Santo.

${ }^{38} \mathrm{O}$ Tribunal Regional Federal da $3^{a}$ Região abrange as seções judiciárias da Justiça Federal nos seguintes Estados: São Paulo e Mato Grosso do Sul.

39 O Tribunal Regional Federal da $4^{\mathrm{a}}$ Região abrange as seções judiciárias da Justiça Federal nos seguintes Estados: Paraná, Santa Catarina e Rio Grande do Sul.

${ }^{40} \mathrm{O}$ Tribunal Regional Federal da $5^{\mathrm{a}}$ Região abrange as seções judiciárias da Justiça Federal nos seguintes Estados: Alagoas, Ceará, Paraíba, Pernambuco, Rio Grande do Norte e Sergipe.
} 
Revista Eletrônica de Direito Processual - REDP.

Rio de Janeiro. Ano 15. Volume 22. Número 2. Maio a Agosto de 2021

Periódico Quadrimestral da Pós-Graduação Stricto Sensu em Direito Processual da UERJ

Patrono: José Carlos Barbosa Moreira (in mem.). ISSN 1982-7636. pp. 120-142

www.redp.uerj.br

dessa dissonância encontra-se no crônico problema de alocação de presos provisórios e definitivos (sem trânsito em julgado e, em alguns casos, com trânsito em julgado) em estabelecimentos policiais.

Dentro do quadro comparativo acima elaborado, nessa ordem e em consonância com os dados do CNJ, vê-se que os Estados com os mais elevados percentuais de presos provisórios são: Sergipe, Rio de Janeiro e Alagoas. A se considerar os Estados cujos percentuais de presos provisórios são superiores à metade dos "presos", tem-se a listagem então acrescida as seguintes unidades: Goiás, Amazonas, Rio Grande do Norte, Paraná e Amapá.

Convém perguntar se os Estados que ostentam os maiores percentuais de presos provisórios ostentam igualmente as mais elevadas proporções de pessoas presas (em geral). Caso se busquem as taxas de encarceramento desses Estados ${ }^{41}$ (calculadas por meio da proporção entre o número de "presos", segundo o DEPEN ${ }^{42,}$ sobre a projeção populacional fornecida pelo $\mathrm{IBGE}^{43}$ ), chega-se a um quadro curioso.

Para provocar reflexão sobre o equacionamento do sistema de justiça criminal e a projeção de criminalidade violenta, projeta-se na última coluna as taxas de homicídio por 100 mil habitantes referentes ao ano de $2017^{44}$ dessas mesmas unidades federativas:

\begin{tabular}{|l|l|l|l|l|}
\hline UF & $\begin{array}{l}\text { População } \\
\text { (IBGE) }\end{array}$ & $\begin{array}{l}\text { Taxa de } \\
\text { encarceramento } \\
\text { (DEPEN/IBGE) })\end{array}$ & $\begin{array}{l}\text { Percentual } \\
\text { de presos } \\
\text { provisórios } \\
(\mathrm{CNJ})\end{array}$ & $\begin{array}{l}\text { Taxas de } \\
\text { homicídio }\end{array}$ \\
\hline SE & 2.319 .281 & 269,22 & $75,70 \%$ & 57,4 \\
\hline RJ & 17.363 .911 & 292,68 & $72,50 \%$ & 38,4 \\
\hline AL & 3.351 .858 & 273,31 & $60,33 \%$ & 53,7 \\
\hline GO & 7.116 .323 & 361,99 & $54,97 \%$ & 42,8 \\
\hline
\end{tabular}

\footnotetext{
${ }^{41}$ A taxa de encarceramento refere-se ao número de pessoas presas por 100 mil habitantes.

${ }^{42}$ A escolha pelo uso da base de dados do Departamento Penitenciário Nacional mostra-se opção parcimoniosa para construção das taxas de encarceramento. Isso porque, se o $\mathrm{CNJ}$ registra números prisionais mais elevados, a taxa de encarceramento calculada sobre os números do BNMP seria sensivelmente mais elevada.

${ }^{43}$ INSTITUTO BRASILEIRO DE GEOGRAFIA E ESTATÍSTICA (IBGE), Projeção da população do Brasil e das Unidades da Federação - Gráfico on-line., Atualização on-line.

${ }^{44}$ INSTITUTO DE PESQUISA ECONÔMICA APLICADA; FÓRUM BRASILEIRO DE SEGURANÇA PÚBLICA, Atlas da violência 2019, Brasília; Rio de Janeiro; São Paulo: IPEA; FBSP, 2019, p. 23.
} 
Revista Eletrônica de Direito Processual - REDP.

Rio de Janeiro. Ano 15. Volume 22. Número 2. Maio a Agosto de 2021

Periódico Quadrimestral da Pós-Graduação Stricto Sensu em Direito Processual da UERJ

Patrono: José Carlos Barbosa Moreira (in mem.). ISSN 1982-7636. pp. 120-142

www.redp.uerj.br

\begin{tabular}{|l|l|l|l|l|}
\hline AM & 4.208 .551 & 258,75 & $53,91 \%$ & 41,2 \\
\hline RN & 3.534 .986 & 291,09 & $53,62 \%$ & 62,8 \\
\hline PR & 11.516 .298 & 259,03 & $53,52 \%$ & 24,4 \\
\hline AP & 861.872 & 319,07 & $52,53 \%$ & 48,0 \\
\hline Brasil & 211.748 .934 & 353,25 & $44,46 \%$ & 31,6 \\
\hline
\end{tabular}

É sintomático que o uso da prisão processual desborde do padrão médio dos Estados justamente naquelas unidades que possuem as piores taxas de congestionamento. Os Estados com percentuais mais elevados de prisão processual não se aproximam da média de encarceramento do país. Prendem "pouco" e o fazem mal (porque sem título de culpa). Além disso, os três Estados (SE, AL, RN) com as maiores taxas de homicídios do país são justamente os Estados com destacadas taxas de prisão processual e taxas de encarceramento abaixo da média nacional.

Não são muitos os estudos que se debruçam sobre o modo assimétrico com que os Estados da Federação fazem uso da prisão.

Sobre a evolução das taxas de encarceramento, Machado, Zackseski e Azevedo indicam, com precisão, que o sistema penitenciário é símbolo das situações de violência e desigualdade de cada país e, quando se cuida especificamente do Brasil, constata-se um total descontrole do crescimento desenfreado do uso da prisão, a colocar em xeque não só os direitos dos presos mas igualmente a credibilidade do sistema penal.45

Essa assertiva é indicativa igualmente das desigualdades regionais do país. Afinal, como visto, os Estados que mais fazem uso da prisão processual não são aqueles que ostentam as taxas de encarceramento mais elevadas.

Merece destaque o estudo de Israel e Pereira, por seu recorte e metodologia, mas cujos dados desafortunadamente já se mostram desatualizados, pois referentes aos números do DEPEN de 2012. Os autores cotejam hipóteses que vão desde a estratificação etária até as opções políticas de voto da população encarcerada, para indicar com clareza que "(...) o encarceramento nos estados brasileiros está relacionado com a proporção de jovens e a taxa

\footnotetext{
${ }^{45}$ ZACKSESKI, Cristina; MACHADO, Bruno Amaral; AZEVEDO, Gabriela, Dimensões do encarceramento e desafios da política penitenciária no Brasil, Revista Brasileira de Ciências Criminais, v. 24, n. 126, p. 291 336, 2016, p. 297-299.
} 
Revista Eletrônica de Direito Processual - REDP.

Rio de Janeiro. Ano 15. Volume 22. Número 2. Maio a Agosto de 2021

Periódico Quadrimestral da Pós-Graduação Stricto Sensu em Direito Processual da UERJ

Patrono: José Carlos Barbosa Moreira (in mem.). ISSN 1982-7636. pp. 120-142

www.redp.uerj.br

de urbanização". ${ }^{46} \mathrm{O}$ crescimento das taxas de encarceramento nos Estados, em geral, ainda que indique sensíveis e assimétricas variações, responde a dois fatores: “(...) capacidade de o Estado fazer valer as regras punitivas e a vontade/inclinação em resolver os conflitos inerentes da fase atual do capitalismo por vias punitivistas". 47

A consideração quantitativa do congestionamento judiciário é dado relativamente recente, pois coincidente com o regime de publicidade ativa do CNJ no monitoramento dos tempos de tramitação dos feitos criminais em primeira instância e nos tribunais (de segunda instância e superiores).

Projetando os dados de encarceramento por Estado, merece destaque o estudo de Suxberger, no qual são cotejados as taxas de encarceramento, consoante dados do CNJ do ano de 2018, os percentuais de prisão processual e os dados de criminalidade violenta. ${ }^{48} \mathrm{~A}$ conclusão é chamativa: os Estados com os mais alarmantes números de criminalidade violenta e de letalidade intencional são unidades que possuem baixas taxas de encarceramento e elevados percentuais de prisão processual.

A variação nas taxas de encarceramento se explica pelo nível de institucionalização do sistema de justiça de cada Estado, ou seja, as diferentes taxas de encarceramento se explicam, mantidas inalteradas todas as outras coisas, pela capacidade do Estado de prender, processar e julgar suspeitos de práticas criminais. ${ }^{49}$ Daí, igualmente, a conclusão de que, quanto maior a sofisticação e o incremento institucional do sistema de justiça criminal, mais alargado o uso da pena de prisão. Se menor a sofisticação e o incremento institucional, temse destacado uso da prisão processual, com reduzida taxa de encarceramento. Essa última hipótese guarda proximidade com o desvio no uso do arcabouço jurídico para a prisão. Com ou sem razão, chega-se ao uso da prisão.

\section{Considerações Finais}

\footnotetext{
46 ISRAEL, Vinicius Pinheiro; PEREIRA, Natasha Bachini, Estudo sobre a distribuição das taxas de encarceramento nos estados brasileiros e principais variáveis associadas: Influências socioeconômicas e ideológicas, Dilemas - Revista de Estudos de Conflito e Controle Social, v. 11, n. 3, p. 385-411, 2018, p. 398. ${ }^{47}$ Ibid., p. 406.

48 SUXBERGER, Antonio Henrique Graciano, O encarceramento em massa no Brasil a partir de suas assimetrias: o que dizem os números e sua relação com a segurança pública, in: SUXBERGER, Antonio Henrique Graciano et al (Orgs.), Segurança pública: os desafios da pós-modernidade, Rio de Janeiro: Lumen Juris, 2019, p. 43-68.

${ }^{49}$ JESUS FILHO, José de; FONSECA, Francisco César Pinto da, Taxa de encarceramento: análise comparativa entre os Estados brasileiros, Revista Brasileira de Administração Política, v. 10, n. 1, p. 99-132, 2017.
} 
Revista Eletrônica de Direito Processual - REDP.

Rio de Janeiro. Ano 15. Volume 22. Número 2. Maio a Agosto de 2021

Periódico Quadrimestral da Pós-Graduação Stricto Sensu em Direito Processual da UERJ

Patrono: José Carlos Barbosa Moreira (in mem.). ISSN 1982-7636. pp. 120-142

www.redp.uerj.br

A prisão processual no Brasil, compreendida como a imposição da prisão ao investigado ou acusado que ainda não foi sentenciado, é fenômeno cuja compreensão não pode ser dimensionada sem igualmente considerar os dados de funcionamento da justiça em primeira instância. Os dados atinentes à prisão processual, cuja compreensão se mostra indissociável da problematização dos tempos e das taxas de congestionamento judiciário, não se mostram precisos e claros suficientemente a possibilitar uma problematização qualificada das alternativas político-criminais de equacionamento de seu uso.

No presente estudo, não se problematizaram os tempos de congestionamento dos feitos criminais nos tribunais, mas apenas em primeira instância. De todo modo, há um ponto que se extrai dos dados de congestionamento em primeira instância. Se a exigibilidade da sentença condenatória só ocorre após o trânsito em julgado, como decidiu o Supremo Tribunal Federal ao revisitar o tema da execução provisória da pena no segundo semestre de $2019,{ }^{50}$ a preocupação com a prisão processual guarda aguda relação com o tempo de solução do processo em primeira instância. Afinal, aquele que respondeu ao processo preso preventivamente inicia o cumprimento de sua reprimenda com a prolação da sentença condenatória $^{51}$; aquele que respondeu ao processo em liberdade, só iniciará o cumprimento de eventual reprimenda quando as partes já não dispuserem mais de recursos contra a condenação.

Nesse sentido, o uso alargado da prisão processual acaba se tornando medida que, aparente e falsamente, "compensa" a má institucionalidade do sistema de justiça: eis uma hipótese que se extrai do cotejo entre as taxas de congestionamento em primeira instância e os percentuais de prisão processual dos Estados que, sabidamente, fazem uso desigual da prisão. O uso alargado da prisão processual, quando comparado com o encarceramento em geral, evidencia que a prisão processual acaba se convertendo, por meio de desvio, numa medida compensatória do fluxo ruim de tramitação da justiça em primeira instância.

\footnotetext{
${ }^{50}$ BRASIL, Supremo Tribunal Federal (STF), Ação Direta de Constitucionalidade no 43, (ADC 43). Distrito Federal. Pleno. Rel. Min. Marco Aurélio. Julgamento em 7 nov. 2019. Acórdão pendente de publicação [julgamento conjunto com as ADCs 44 e 53].

${ }^{51}$ BRASIL, Súmula 716: Admite-se a progressão de regime de cumprimento da pena ou a aplicação imediata de regime menos severo nela determinada, antes do trânsito em julgado da sentença condenatória. Pleno, 24 set. 2003.
} 
Revista Eletrônica de Direito Processual - REDP.

Rio de Janeiro. Ano 15. Volume 22. Número 2. Maio a Agosto de 2021

Periódico Quadrimestral da Pós-Graduação Stricto Sensu em Direito Processual da UERJ

Patrono: José Carlos Barbosa Moreira (in mem.). ISSN 1982-7636. pp. 120-142

www.redp.uerj.br

A par do necessário debate a respeito do equacionamento normativo da prisão processual, a análise dos números diz bastante sobre vetores que, conquanto não jurídicos ou traduzíveis em categorias próprias da literatura do processual penal, certamente influenciam o processo decisório que culmina na imposição da prisão processual nos casos submetidos ao sistema de justiça.

Nos cenários de maior institucionalidade, esse uso se dá em conformidade com a ordem legal - e, nesse caso, as razões de eventual discussão quanto ao uso abusivo ou tolerado da prisão dá-se numa margem político-criminal situada na atuação legiferante. Nos contextos de baixa institucionalidade, o uso da prisão - porque provisória - dá-se com indicativo de que o sistema de justiça criminal mal processa ou não processa de modo regular os fatos que lhes são notificados e cuja resposta penal seja então formalizada. Os tempos de processo se alargam, a prisão se prolonga e aí, nesse caso, o uso da prisão deriva de uma institucionalidade ruim, a margem ou contrariamente ao que dispõe a modelagem jurídica que estabelece o uso (em tese, afirmado como excepcional) da prisão.

\section{REFERÊNCIAS}

BRASIL. Conselho Nacional de Justiça (CNJ). Justiça em Números 2019. Relatório Analítico [recurso on-line]. Brasília: CNJ, 2019. Disponível em: https://www.cnj.jus.br/wpcontent/uploads/conteudo/arquivo/2019/08/justica_em_numeros20190919.pdf. Acesso em: 3 jul. 2020.

BRASIL. Conselho Nacional de Justiça (CNJ). Justiça em Números 2019: Sumário Executivo [recurso on-line]. Brasília: CNJ, 2019. Disponível em: https://www.cnj.jus.br/wpcontent/uploads/conteudo/arquivo/2019/08/8ee6903750bb4361b5d0d1932ec6632e.p df. Acesso em: 3 jul. 2020.

BRASIL. Conselho Nacional de Justiça (CNJ). Manual Prático de Rotinas das Varas Criminais e de Execução Penal: Elaborado de acordo com o plano de gestão para o funcionamento das varas criminais e de execução penal. Brasília: CNJ, 2009. 
Revista Eletrônica de Direito Processual - REDP.

Rio de Janeiro. Ano 15. Volume 22. Número 2. Maio a Agosto de 2021

Periódico Quadrimestral da Pós-Graduação Stricto Sensu em Direito Processual da UERJ

Patrono: José Carlos Barbosa Moreira (in mem.). ISSN 1982-7636. pp. 120-142

www.redp.uerj.br

Disponível em: https://www.cnj.jus.br/wp-content/uploads/2011/02/manual-rotinavaras-criminais-cnj.pdf. Acesso em: 3 jul. 2020.

BRASIL. Conselho Nacional de Justiça (CNJ). Portal do BNMP [Banco Nacional de Mandados de Prisão]. Versão 1.15.1 [recurso on-line]. Brasília: CNJ, 2020. Disponível em: https://portalbnmp.cnj.jus.br/\#/estatisticas. Acesso em: 3 jul. 2020.

BRASIL. Conselho Nacional do Ministério Público (CNMP). O Ministério Público e o controle externo da Atividade Policial: Dados 2016 [recurso eletrônico]. Brasília: CNMP, 2017. Disponível em: http://www.cnmp.mp.br/portal/publicacoes/245cartilhas-e-manuais/10913-o-ministerio-publico-e-o-controle-externo-da-atividadepolicial-dados-2016. Acesso em: 3 jul. 2020.

BRASIL. Conselho Nacional do Ministério Público (CNMP). Sistema Prisional em Números. Relatórios BI - Resolução CNMP 56/2010. Versão compilada e atualizada on-line. Atualização on-line. Disponível em: http://www.cnmp.mp.br/portal/relatoriosbi/sistema-prisional-em-numeros. Acesso em: 3 jul. 2020.

BRASIL. Ministério da Justiça e Segurança Pública. Departamento Penitenciário Nacional (DEPEN). Levantamento Nacional de Informações Penitenciárias: INFOPEN Atualização — Dezembro de 2019. Brasília: DEPEN, 2019. Disponível em: https://app.powerbi.com/view?r=eyJrIjoiZTlkZGJjODQtNmJlMi00OTJhLWFIMDkt NzRINmFkNTM0MWI3IiwidCI6ImViMDkwNDIwLTQ0NGMtNDNmNy05MWY yLTRiOGRhNmJmZThlMSJ9. Acesso em: 3 jul. 2020.

BRASIL. Supremo Tribunal Federal (STF). Ação Direta de Constitucionalidade no 43, (ADC 43). Distrito Federal. Pleno. Rel. Min. Marco Aurélio. Julgamento em 7 nov. 2019. Acórdão pendente de publicação [julgamento conjunto com as ADCs 44 e 53].

BRASIL. Supremo Tribunal Federal (STF). Medida Cautelar na Arguição de Descumprimento de Preceito Fundamental no 347 (ADPF 347 MC). Distrito Federal. Pleno. Rel. Min. Marco Aurélio. Julgamento em 9 set. 2015. Disponível em: http://redir.stf.jus.br/paginadorpub/paginador.jsp?docTP=TP\&docID=10300665. Acesso em: 3 jul. 2020.

BRASIL. Supremo Tribunal Federal (STF). Súmula 716: Admite-se a progressão de regime de cumprimento da pena ou a aplicação imediata de regime menos severo nela 
Revista Eletrônica de Direito Processual - REDP.

Rio de Janeiro. Ano 15. Volume 22. Número 2. Maio a Agosto de 2021

Periódico Quadrimestral da Pós-Graduação Stricto Sensu em Direito Processual da UERJ

Patrono: José Carlos Barbosa Moreira (in mem.). ISSN 1982-7636. pp. 120-142

www.redp.uerj.br

determinada, antes do trânsito em julgado da sentença condenatória. Pleno, 24 set. 2003.

Disponível

em:

http://www.stf.jus.br/portal/jurisprudencia/menuSumarioSumulas.asp?sumula=3637

$\&$ termo=. Acesso em: 3 jul. 2020.

BRASIL. Supremo Tribunal Federal (STF). Súmula Vinculante 56: A falta de estabelecimento penal adequado não autoriza a manutenção do condenado em regime prisional mais gravoso, devendo-se observar, nessa hipótese, os parâmetros fixados no RE 641.320/RS. Pleno, 29 ago. 2016. Disponível em: https://jurisprudencia.stf.jus.br/pages/search/seq-sumula815/false. Acesso em: 3 jul. 2020

BUCCI, Maria Paula Dallari. Fundamentos para uma teoria jurídica das políticas públicas. São Paulo: Saraiva, 2013.

CRESPO, André Pereira; VARELLA, Marcelo Dias. A insuficiência das políticas públicas no sistema penitenciário para responder ao estado de coisas inconstitucional: um problema comum a todos os poderes. R. Fac. Dir. UFG, v. 43, p. 1-24, 2019.

GUSTÍN, Miracy Barbosa de Sousa; DIAS, Maria Tereza Fonseca. (Re)pensando a pesquisa jurídica: teoria e prática. 3. ed. Belo Horizonte: Del Rey, 2010.

HEARD, Catherine; FAIR, Helen. Pre-trial detention and its over-use: evidence from ten countries. Londres: ICPR; University of London, 2019.

INSTITUTO FOR CRIMINAL POLICY RESEARCH (ICPR). Birbeck University of London. World Prison Brief (WPF) data. Highest to Lowest. [recurso eletrônico]. Londres: Birbeck University of London, 2020. Disponível em: http://www.prisonstudies.org/highest-to-lowest/prison-population-total. Acesso em: 3 jul. 2020.

INSTITUTO BRASILEIRO DE GEOGRAFIA E ESTATÍSTICA (IBGE). Projeção da população do Brasil e das Unidades da Federação - Gráfico on-line. Atualização online. Disponível em: <https://www.ibge.gov.br/apps/populacao/projecao/>. Acesso em: 7 jul. 2020.

INSTITUTO DE PESQUISA ECONÔMICA APLICADA; FÓRUM BRASILEIRO DE SEGURANÇA PÚBLICA. Atlas da violência 2019. Brasília; Rio de Janeiro; São Paulo: IPEA; FBSP, 2019. 
Revista Eletrônica de Direito Processual - REDP.

Rio de Janeiro. Ano 15. Volume 22. Número 2. Maio a Agosto de 2021

Periódico Quadrimestral da Pós-Graduação Stricto Sensu em Direito Processual da UERJ

Patrono: José Carlos Barbosa Moreira (in mem.). ISSN 1982-7636. pp. 120-142

www.redp.uerj.br

ISRAEL, Vinicius Pinheiro; PEREIRA, Natasha Bachini. Estudo sobre a distribuição das taxas de encarceramento nos estados brasileiros e principais variáveis associadas: Influências socioeconômicas e ideológicas. Dilemas - Revista de Estudos de Conflito e Controle Social, v. 11, n. 3, p. 385-411, 2018.

JESUS FILHO, José de; FONSECA, Francisco César Pinto da. Taxa de encarceramento: análise comparativa entre os Estados brasileiros. Revista Brasileira de Administração Política, v. 10, n. 1, p. 99-132, 2017.

KULLER, Laís; DIAS, Camila. O papel do preso nas audiências de custódia: Protagonista ou marginal? Dilemas - Revista de Estudos de Conflito e Controle Social, v. 12, n. 2, p. 267-287, 2019.

LAGES, Lívia Bastos; RIBEIRO, Ludmila; LAGES, Lívia Bastos; et al. Os determinantes da prisão preventiva na Audiência de Custódia: reforço de estereótipos sociais? Revista Direito GV, v. 15, n. 3, 2019. Disponível em: $<$ http://www.scielo.br/scielo.php?script=sci_abstract\&pid=S180824322019000300207\&lng=pt\&nrm=iso\&tlng=pt>. Acesso em: 16 dez. 2019.

PASTANA, Débora Regina. Estado punitivo brasileiro: A indeterminação entre democracia e autoritarismo. Civitas - Revista de Ciências Sociais, v. 13, n. 1, p. 27-47, 2013.

PASTANA, Debora Regina. Os contornos do Estado punitivo no Brasil. Revista da Faculdade de Direito UFPR, v. 46, n. 0, p. 207-221, 2007.

SUXBERGER, Antonio Henrique Graciano. O encarceramento em massa no Brasil a partir de suas assimetrias: o que dizem os números e sua relação com a segurança pública. In: SUXBERGER, Antonio Henrique Graciano; SANTOS, Leonardo Augusto de A. Cezar dos; BALLAN JÚNIOR, Octahydes; et al (Orgs.). Segurança pública: os desafios da pós-modernidade. Rio de Janeiro: Lumen Juris, 2019, p. 43-68.

WERNER, Patricia Ulson Pizarro. A abordagem Direito e Políticas Públicas como ferramenta de aprimoramento das instituições jurídicas: qualidade organizacional, sistematização de dados e fomento das relações interinstitucionais. REI - Revista Estudos Institucionais, v. 5, n. 3, p. 926-941, 2019.

ZACKSESKI, Cristina; MACHADO, Bruno Amaral; AZEVEDO, Gabriela. Dimensões do encarceramento e desafios da política penitenciária no Brasil. Revista Brasileira de Ciências Criminais, v. 24, n. 126, p. 291-336, 2016. 